\begin{tabular}{|c|c|c|c|}
\hline \multirow{2}{*}{$\begin{array}{r}\text { Case Reports in } \\
\text { Gastroenterology }\end{array}$} & \multicolumn{2}{|c|}{ Case Rep Gastroenterol 2016;10:81-87 } & \multirow[b]{2}{*}{$\begin{array}{l}\text { Karger } \\
\text { Open access }\end{array}$} \\
\hline & $\begin{array}{l}\text { DOI: } 10.1159 / 000444275 \\
\text { Publisnea onine: IVlay } 19,2016\end{array}$ & $\begin{array}{l}\text { (C) } 2016 \text { The Author(s) } \\
\text { Published by S. Karger AG, Basel } \\
\text { www.karger.com/crg }\end{array}$ & \\
\hline & \multicolumn{2}{|c|}{$\begin{array}{l}\text { This article is licensed under the Creative Commons Attribution-NonCommercial } 4.0 \\
\text { International License (CC BY-NC) (http://www.karger.com/Services/OpenAccessLicense). } \\
\text { Usage and distribution for commercial purposes requires written permission. }\end{array}$} & \\
\hline
\end{tabular}

\title{
Gastrointestinal Zygomycosis Masquerading as Acute Appendicitis
}

\author{
Won-Tak Choi ${ }^{\mathrm{a}}$ Tammy T. Chang ${ }^{\mathrm{b}}$ Ryan M. Gill \\ ${ }^{a}$ Department of Pathology, University of California at San Francisco, San \\ Francisco, Calif., USA; ${ }^{\mathrm{b}}$ Department of Surgery, University of California at San Francisco, \\ San Francisco, Calif., USA
}

\section{Keywords}

Zygomycosis $\cdot$ Absidia spp. $\cdot$ Appendicitis $\cdot$ Fungal sepsis $\cdot$ Neutropenia

\begin{abstract}
Zygomycosis is a rare invasive opportunistic fungal infection that occurs in the setting of hematologic malignancies, chemotherapy-induced neutropenia, and immunosuppressive therapies. We report the first case of disseminated appendiceal zygomycosis due to Absidia spp. in a neutropenic patient who initially presented as acute appendicitis. A 63-year-old woman with acute myeloid leukemia presented as acute appendicitis while receiving induction chemotherapy and ultimately succumbed to overwhelming disseminated zygomycosis. Initial symptoms included loose stools and right lower abdominal pain unresponsive to broad-spectrum antibiotics. Clinical examination and cross-sectional imaging suggested acute appendicitis. The final diagnosis was established by histological evaluations of the ileocecectomy specimen, which showed angioinvasive fungal organisms within the necrotic appendiceal wall with characteristics typical of zygomycetes. Fungal cultures demonstrated Absidia spp. The patient was treated with amphotericin B but expired in the setting of fungal sepsis. A diagnosis of a fungal infection, including zygomycosis, should be considered in all chemotherapy-induced neutropenic patients who present with symptoms of acute appendicitis. A high index of clinical suspicion with prompt histologic and culture diagnosis of zygomycosis may reduce the high mortality and morbidity associated with zygomycosis of the gastrointestinal tract.

(C) 2016 The Author(s)

Published by S. Karger AG, Basel
\end{abstract}

KARGER 


\section{Case Reports in \\ Gastroenterology}

Case Rep Gastroenterol 2016;10:81-87

(c) 2016 The Author(s). Published by S. Karger AG, Basel www.karger.com/crg

Choi et al:: Gastrointestinal Zygomycosis Masquerading as Acute Appendicitis

\section{Introduction}

Zygomycosis is an uncommon but often fatal opportunistic fungal infection that occurs in the setting of hematologic malignancies, chemotherapy-induced neutropenia, hematopoietic stem cell transplantation, immunosuppressive therapies, diabetes mellitus, and solid organ transplantation [1-6]. Preterm infants are also at risk of developing zygomycosis due to general immune incompetence [7]. The class Zygomycetes consists of two orders: Mucorales and Entomophthorales [2]. Mucorales are further divided into two main families: $\mathrm{Mu}$ coraceae and Cunninghamellaceae. Infection caused by Mucorales is called zygomycosis [2]. The members of Mucoraceae, which include Rhizopus, Rhizomucor, Mucor, and Absidia, cause the vast majority of zygomycosis [2].

Zygomycetes are ubiquitous in nature [2]. Spores are released into the air, rapidly germinate, and gain entry through inoculation of respiratory mucosa, skin, or gastrointestinal (GI) tract, ultimately causing angioinvasion (leading to hematogenous dissemination), thrombosis, infarction, and necrosis $[2,8]$. The main manifestations of disease include rhinocerebral, pulmonary, cutaneous/subcutaneous, and disseminated diseases, with the first two being the most common forms of infection [2, 8]. GI infection is relatively uncommon, but gastric [5, 6], small bowel [9], ileocecum [4, 10], colon [5], or liver [9] involvement has been reported. A case of primary GI zygomycosis due to Absidia spp. mimicking necrotizing enterocolitis in a preterm infant has also been reported [7].

GI zygomycosis typically presents with nonspecific symptoms, including abdominal pain, nausea, dyspepsia, vomiting, bloody diarrhea, upper GI bleeding, abdominal distension, intestinal obstruction, and perforation peritonitis $[5,6,10]$, making early antemortem diagnosis very difficult. As such, zygomycosis of the GI tract is associated with high mortality and morbidity [5]. A high index of suspicion is required for early diagnosis, especially in the presence of predisposing conditions, such as hematologic malignancies, neutropenia, diabetes mellitus, and immunosuppressive therapies [1-6].

We report a case of disseminated appendiceal zygomycosis in a neutropenic patient who initially presented as acute appendicitis during induction chemotherapy for acute myeloid leukemia (AML) and highlight features that may lead to earlier diagnosis. To our knowledge, appendiceal zygomycosis due to Absidia spp. mimicking acute appendicitis has never been reported in the literature.

\section{Case Presentation}

A 63-year-old woman with relapsed AML and diabetes mellitus was admitted for induction chemotherapy with cytarabine and clofarabine as part of the management plan for allogeneic stem cell transplantation. Six days after chemotherapy, she developed loose stools and diffuse abdominal pain. She was found to have Clostridium difficile infection, and oral metronidazole treatment was started. Her abdominal pain persisted and began to localize to the right lower quadrant. She was neutropenic but remained afebrile. An abdominal and pelvic computer tomography (CT) scan showed a segmental hypoenhancing area in the mid appendix with minimal surrounding fat stranding concerning for appendicitis. There were no drainable fluid collections (fig. 1a). Given the patient's high risk of perioperative morbidity and mortality, she was initially treated with broad-spectrum intravenous antibiotics consisting of meropenem. The patient remained afebrile and hemodynamically normal on medical treatment. However, her right lower quadrant abdominal pain continued and she develo- 
ped localized peritoneal signs. A repeat CT scan obtained 3 days later showed stable inflammation of the appendix with a new finding of an adjacent loop of small bowel with thickened wall. There remained no extraluminal air or drainable fluid collections to suggest perforation (fig. 1b). Since the patient was not responding to medical therapy, she was taken urgently to the operating room for an appendectomy for treatment of acute appendicitis.

The operation began with a laparoscopic approach. Upon inspection of the right lower quadrant, the appendix was found to be completely necrotic down to the base. The necrotic appendix was lying on top of an adjacent loop of terminal ileum that was also segmentally necrotic at the contacting surface (fig. 2). The case was converted to open in order to perform an ileocecectomy with primary stapled anastomosis. The fascia was closed but the skin was left open to heal by secondary intention due to the infected wound classification.

The patient was admitted to the intensive care unit postoperatively and extubated on postoperative day (POD) 1. Despite empiric broad-spectrum antimicrobial therapy with meropenem, linezolid, and fluconazole, the patient spiked a fever to $38.5^{\circ} \mathrm{C}$ on POD2. She clinically deteriorated on POD4 and was re-intubated for tachypnea and hypoxia. A CT scan of the chest showed numerous peripheral cavitary lesions that were either septic emboli or fungal infection. A bronchoalveolar lavage was performed to aid diagnosis.

On POD5, pathological diagnosis of zygomycosis was made from the ileocecectomy specimen. Hematoxylin and eosin (H\&E)-stained sections showed ischemic changes, hemorrhage, and thrombosed vessels filled with broad irregular aseptate hyphae (fig. 3a, b). Inflammatory cells were rare as expected in a neutropenic patient. Gomori methenamine silver (GMS)-stained sections also demonstrated characteristic wide ribbon-like aseptate hyphae that branch at wide angles, typical of Zygomycetes, involving both vessels and adjacent submucosa (fig. 3C) as well as invading through the muscularis propria of the appendix (fig. 3D). Antifungal therapy was immediately switched to amphotericin $B$.

On POD6, fungal overgrowth was found in the surgical wound. Culture of the bronchoalveolar lavage recovered Absidia spp., confirming disseminated angioinvasive zygomycosis. The patient's clinical condition continued to worsen with severe hypotension that required increasing doses of vasopressors. Given the patient's dismal prognosis of surviving such an overwhelming systemic fungal infection, goals of care were transitioned to comfort and she expired on POD8.

\section{Discussion}

We report an unusual presentation of disseminated GI zygomycosis initially presenting as acute appendicitis in a neutropenic patient with relapsed AML. To our knowledge, appendiceal zygomycosis due to Absidia spp. mimicking acute appendicitis has never been reported in the literature. Absidia spp. is ubiquitous in nature and found in soil, decaying organic matter, cotton, and many different grains, seeds, and nuts [2]. It is a rare pathogen of the order Mucorales, accounting for only 2-3\% of all Zygomycete infections, and shows almost no pathogenicity in immunocompetent hosts [2]. Infections with Absidia spp. usually occur in immunocompromised hosts, including leukemia or lymphoma patients, especially in the setting of chemotherapy-induced neutropenia and broad-spectrum antibiotics [11, 12]. Although 7\% of all Zygomycete infections are known to involve the GI tract [2], zygomycosis due to Absidia spp. (absidiomycosis) is extremely rare in these sites, even in patients with leukemia or lymphoma [9]. 
Disseminated zygomycosis is associated with a mortality rate of approximately $96 \%$ [13]. Several disseminated infections with Absidia spp. have been reported, including a case of brain abscess following bone marrow transplantation [14] as well as a case of metastatic carcinoma with disseminated zygomycosis involving the brain, lungs, and heart [15]. Although it involved a different member of Mucoraceae, one case of zygomycosis caused by Mucor indicus, presenting as an appendiceal mass with spread to the liver, has been reported as well [4].

The diagnosis of zygomycosis requires demonstration of characteristic wide ribbon-like aseptate hyphae that branch at wide angles $\left(45-90^{\circ}\right)$, especially with fungal specific stains such as GMS stain, and should be supported by culture [2]. Vascular invasion resulting in thrombus formation with infarction, necrosis, and hemorrhage is the most characteristic feature of zygomycosis [2]. Disseminated zygomycosis rapidly invades vessels to spread to multiple organs, most frequently involving the lung [2, 3]. Successful treatment of zygomycosis has been attributed to early diagnosis, aggressive surgical intervention with resection of the involved tissue, and antifungal therapy with amphotericin B [2]. Since surgery is most effective in the setting of localized disease without dissemination [13], early diagnosis is crucial in reducing the high mortality associated with zygomycosis. Pathology of the resected ileocecectomy specimen played a crucial role in diagnosing zygomycosis in this case, leading to the initiation of amphotericin B as the appropriate antifungal therapy. However, the patient developed fatal disease with evidence of dissemination to the lung and abdominal surgical wound at the time of diagnosis.

In conclusion, a diagnosis of a fungal infection, including zygomycosis, should be considered in all chemotherapy-induced neutropenic patients who present with symptoms of acute appendicitis. This is further supported by a previous study reporting that immune defects, especially absolute neutrophil count $<1,000 / \mu \mathrm{l}$, is a major risk factor for the development of fungal disease [3]. A high index of clinical suspicion with prompt histologic and culture diagnosis of zygomycosis may lead to earlier surgical and/or antifungal treatment that can potentially reduce the high mortality and morbidity associated with GI zygomycosis.

\section{Statement of Ethics}

The authors declare that they have no ethical conflicts to disclose. Since the patient died, written informed consent was obtained from her next of kin for publication of this case report and any accompanying images.

\section{Disclosure Statement}

The authors declare that they have no conflicts of interest.

\section{References}

1 Meyer RD, Rosen P, Armstrong D: Phycomycosis complicating leukemia and lymphoma. Ann Intern Med 1972;77:871-879.

2 Ribes JA, Vanover-Sams CL, Baker DJ: Zygomycetes in human disease. Clin Microbiol Rev 2000;13:236301.

3 Brown AE: Overview of fungal infections in cancer patients. Semin Oncol 1990;17(3 suppl 6):2-5. 


\section{Case Reports in \\ Gastroenterology}

\begin{tabular}{l|l}
\hline Case Rep Gastroenterol 2016;10:81-87 \\
\hline $10.1159 / 000444275$ & $\begin{array}{l}\text { @ 2016 The Author(s). Published by S. Karger AG, Basel } \\
\text { www.karger.com/crg }\end{array}$ \\
\hline
\end{tabular}

Choi et al.: Gastrointestinal Zygomycosis Masquerading as Acute Appendicitis

-4 ter Borg F, Kuijper EJ, van der Lelie H: Fatal mucormycosis presenting as an appendiceal mass with metastatic spread to the liver during chemotherapy-induced granulocytopenia. Scand J Infect Dis 1990;22:499-501.

5 Sharma MC, Gill SS, Kashyap S, Kataria R, Gupta DK, Sahni P, Acharya SK: Gastrointestinal mucormycosis - an uncommon isolated mucormycosis. Indian J Gastroenterol 1998;17:131-133.

-6 Irtan S, Lamerain M, Lesage F, Verkarre V, Bougnoux ME, Lanternier F, Zahar JR, Salvi N, Talbotec C, Lortholary O, Lacaille F, Chardot C: Mucormycosis as a rare cause of severe gastrointestinal bleeding after multivisceral transplantation. Transpl Infect Dis 2013;15:E235-E238.

-7 Diven SC, Angel CA, Hawkins HK, Rowen JL, Shattuck KE: Intestinal zygomycosis due to Absidia corymbifera mimicking necrotizing enterocolitis in a preterm neonate. J Perinatol 2004;24:794-796.

-8 Spellberg B, Edwards JJ, Ibrahim A: Novel perspectives on mucormycosis: pathophysiology, presentation, and management. Clin Microbiol Rev 2005;18:556-569.

-9 Suh IW, Park CS, Lee MS, Lee JH, Chang MS, Woo JH, Lee IC, Ryu JS: Hepatic and small bowel mucormycosis after chemotherapy in a patient with acute lymphocytic leukemia. J Korean Med Sci 2000;15:351-354.

10 Baig WW, Ravindra Prabhu A, Natraj KS, Mathew M: Combined mucormycosis and candidiasis of the cecum presenting as a right iliac fossa mass in a patient with chronic kidney disease. Travel Med Infect Dis 2008;6:145-147.

11 Bodey GP, Anaissie E, Gutterman J, Vadhan-Raj S: Role of granulocyte-macrophage colony-stimulating factor as adjuvant therapy for fungal infection in patients with cancer. Clin Infect Dis 1993;17:705-707.

12 Lopes JO, Pereira DV, Streher LA, Fenalte AA, Alves SH, Benevenga JP: Cutaneous zygomycosis caused by Absidia corymbifera in a leukemic patient. Mycopathologia 1995;130:89-92.

13 Tedder M, Spratt JA, Anstadt MP, Hegde SS, Tedder SD, Lowe JE: Pulmonary mucormycosis: results of medical and surgical therapy. Ann Thorac Surg 1994;57:1044-1050.

$\checkmark 14$ Hagensee ME, Bauwens JE, Kjos B, Bowden RA: Brain abscess following marrow transplantation: experience at the Fred Hutchinson Cancer Research Center, 1984-1992. Clin Infect Dis 1994;19:402408.

15 El-Ani AS, Dhar V: Disseminated mucormycosis in a case of metastatic carcinoma. Am J Clin Pathol 1982;77:110-114. 


\section{Case Reports in Gastroenterology \\ Case Rep Gastroenterol 2016;10:81-87 \\ (C) 2016 The Author(s). Published by S. Karger AG, Basel www.karger.com/crg \\ Choi et al.: Gastrointestinal Zygomycosis Masquerading as Acute Appendicitis}
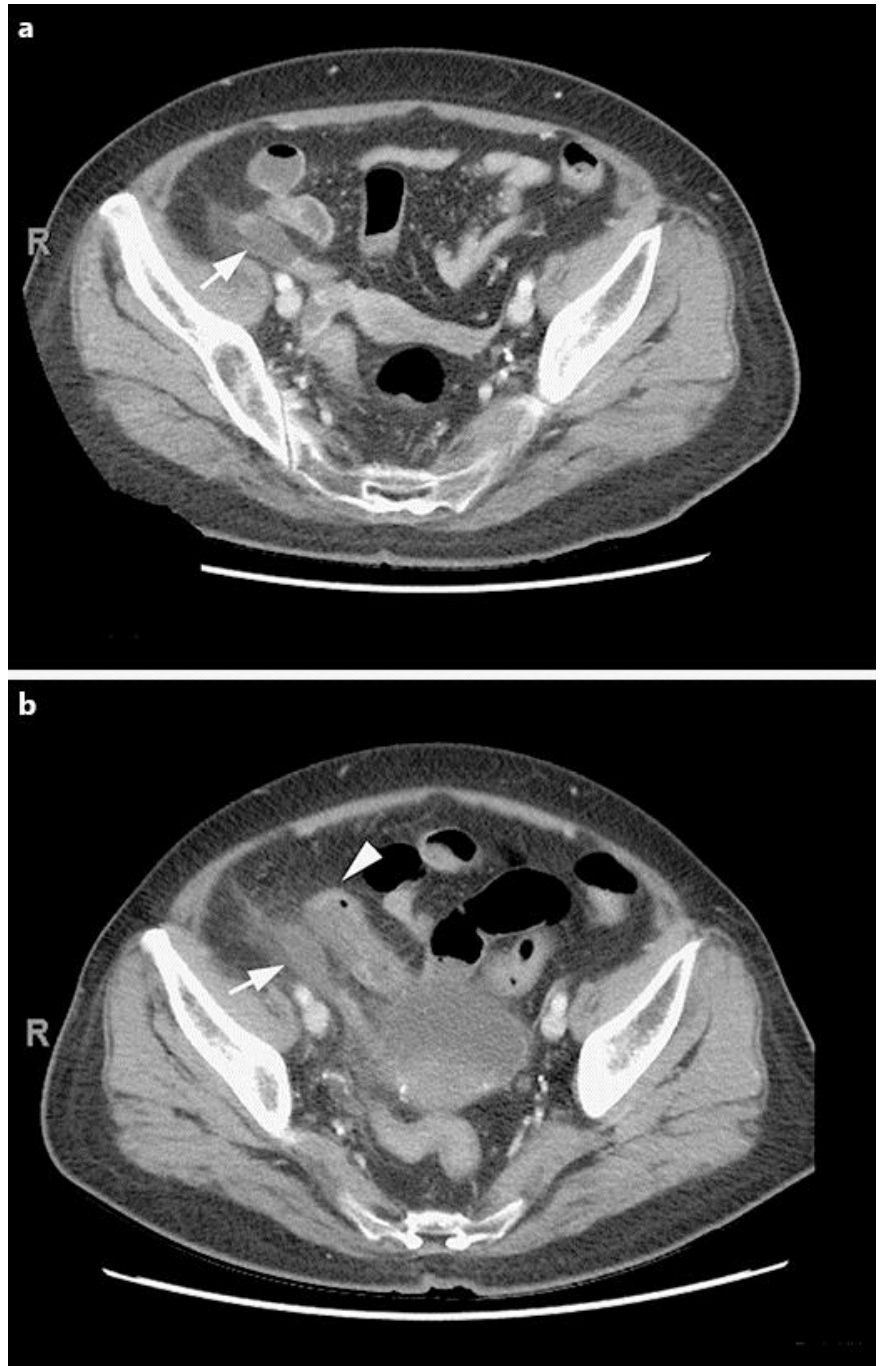

Fig. 1. Abdominal pelvis CT scan. a Initial CT scan showing dilated appendix with hypoenhancing wall (arrow) and minimal surrounding fat stranding. There were no drainable fluid collections. b Repeat CT scan 3 days later showing dilated appendix with hypoenhancing wall (arrow), now with an adjacent loop of small bowel with thickened wall (arrowhead). There remained no drainable fluid collections, no free fluid, and no free air. 


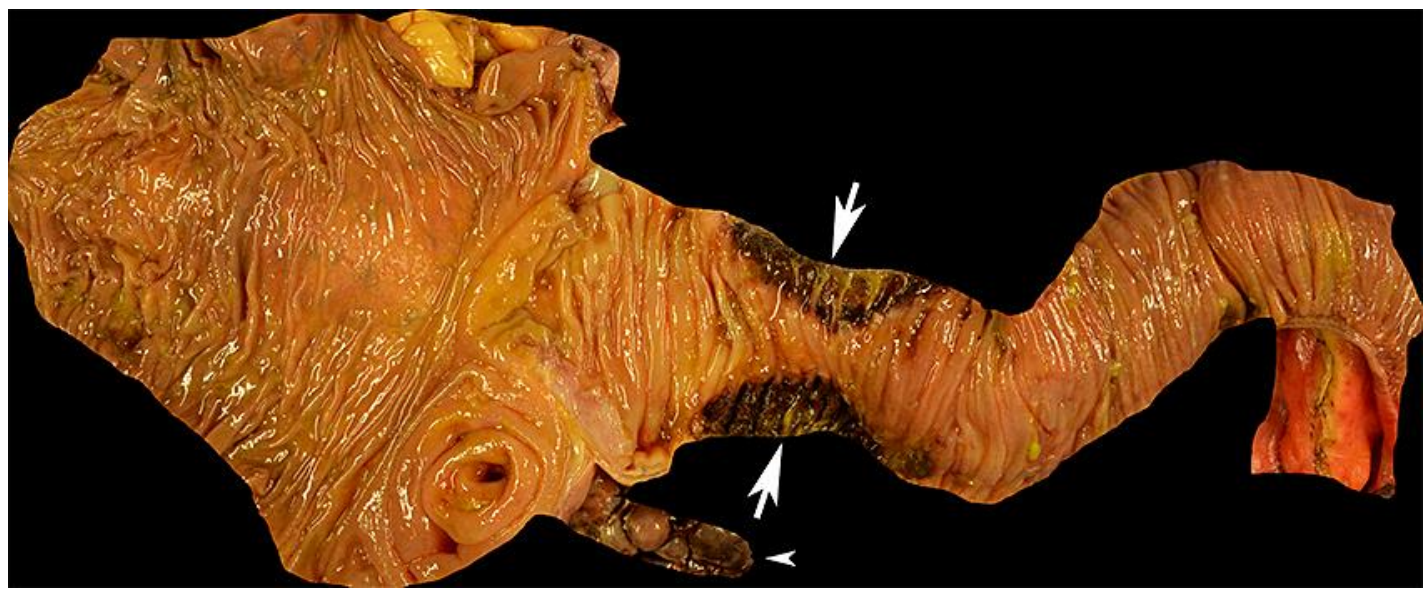

Fig. 2. Ileocecectomy specimen. The appendix was completely necrotic (arrowhead) as was a segment of ileum that was in direct contact with the appendix (arrows).

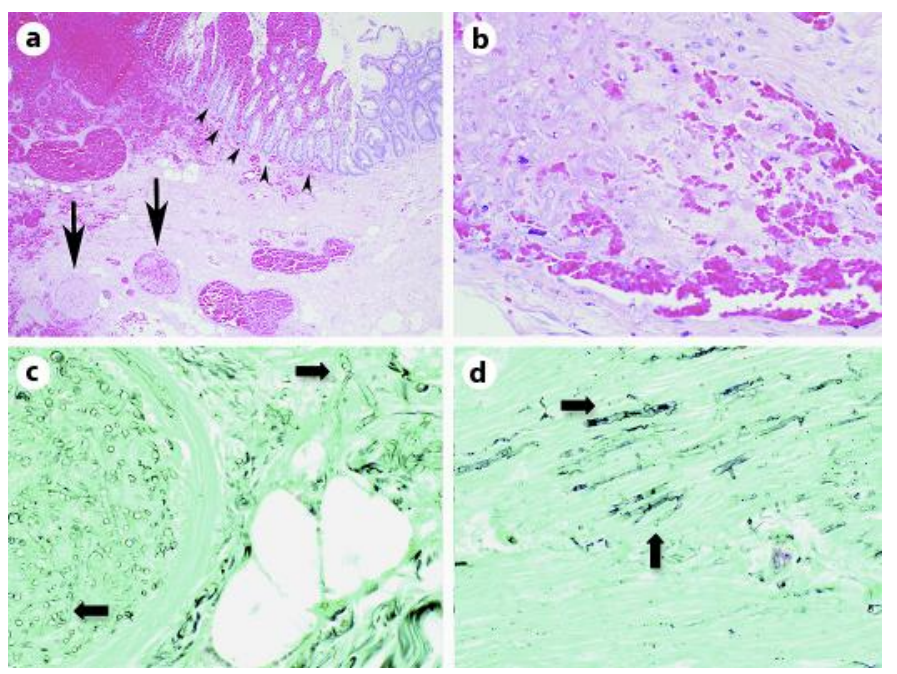

Fig. 3. Microscopic examination of the ileocecectomy specimen. a H\&E-stained section shows thrombosed vessels (arrows) and ischemic changes associated with hemorrhage (arrowheads). $\times 4$. b H\&E-stained section of a vessel filled with hyphae in a patient with neutropenia. Inflammatory cells are largely absent. Pale-staining hyphae that do not stain well with H\&E often look like bubbles or holes in the tissue. $\times 40$. c GMS-stained section of a vessel containing fungal hyphae that also involve adjacent submucosa. Characteristic wide ribbon-like aseptate hyphae with broad-angle branching are seen (arrows). $\times 40$. d GMSstained section of fungal hyphae (arrows) in the muscularis propria of the appendix. $\times 40$. 